Article

\title{
Rapid Microwave Synthesis, Characterization and Reactivity of Lithium Nitride Hydride, $\mathrm{Li}_{4} \mathrm{NH}$
}

\author{
Nuria Tapia-Ruiz ${ }^{1}$, Natalie Sorbie ${ }^{1}$, Nicolas Vaché ${ }^{1,2}$, Tuan K. A. Hoang ${ }^{1}$ \\ and Duncan H. Gregory ${ }^{1}$ **
}

1 WestCHEM, School of Chemistry, University of Glasgow, Glasgow G12 8QQ, UK;

E-Mails: nuria.tapia@glasgow.ac.uk (N.T.-R.); natsor@chem.gla.ac.uk (N.S.); tuan.hoang@glasgow.ac.uk (T.K.A.H)

2 Ecole Nationale Supérieure de Chimie de Clermont-Ferrand, Université Blaise Pascal, BP 187, Aubière Cedex 63174, France; E-Mail: nicolas.vache@ensccf.fr

* Author to whom correspondence should be addressed; E-Mail: Duncan.Gregory@glasgow.ac.uk; Tel.: +44-141-330-6438; Fax: +44-141-330-4888.

Received: 8 October 2013; in revised form: 23 October 2013 / Accepted: 11 November 2013 / Published: 21 November 2013

\begin{abstract}
Lithium nitride hydride, $\mathrm{Li}_{4} \mathrm{NH}$, was synthesised from lithium nitride and lithium hydride over minute timescales, using microwave synthesis methods in the solid state for the first time. The structure of the microwave-synthesised powders was confirmed by powder X-ray diffraction [tetragonal space group $I 4_{1} / a ; a=4.8864(1) \AA, c=9.9183(2) \AA$ ] and the nitride hydride reacts with moist air under ambient conditions to produce lithium hydroxide and subsequently lithium carbonate. $\mathrm{Li}_{4} \mathrm{NH}$ undergoes no dehydrogenation or decomposition [under $\operatorname{Ar}_{(\mathrm{g})}$ ] below $773 \mathrm{~K}$. A tetragonal-cubic phase transition, however, occurs for the compound at $c a .770 \mathrm{~K}$. The new high temperature (HT) phase adopts an anti-fluorite structure (space group $F m \overline{3} m ; a=4.9462(3) \AA$ ) with $\mathrm{N}^{3-}$ and $\mathrm{H}^{-}$ions disordered on the $4 a$ sites. Thermal treatment of $\mathrm{Li}_{4} \mathrm{NH}$ under nitrogen yields a stoichiometric mixture of lithium nitride and lithium imide $\left(\mathrm{Li}_{3} \mathrm{~N}\right.$ and $\mathrm{Li}_{2} \mathrm{NH}$ respectively).
\end{abstract}

Keywords: nitride; hydride; structure; microwaves; synthesis; hydrogen storage; diffraction; thermal analysis; reactivity 


\section{Introduction}

The $\mathrm{Li}-\mathrm{N}-\mathrm{H}$ system is a promising hydrogen storage candidate, with the ability to store $11.5 \mathrm{wt} \%$ of $\mathrm{H}_{2}$ reversibly [1]. This process occurs via two exothermic steps (Equations 1 and 2):

$$
\begin{array}{ll}
\mathrm{Li}_{3} \mathrm{~N}+\mathrm{H}_{2} \rightarrow \mathrm{Li}_{2} \mathrm{NH}+\mathrm{LiH} & \Delta \mathrm{H}=-165 \mathrm{~kJ} / \mathrm{mol} \mathrm{H}_{2} \\
\mathrm{Li}_{2} \mathrm{NH}+\mathrm{H}_{2} \rightarrow \mathrm{LiNH}_{2}+\mathrm{LiH} & \Delta \mathrm{H}=-44.5 \mathrm{~kJ} / \mathrm{mol} \mathrm{H}_{2}
\end{array}
$$

However, it has been demonstrated that the reaction pathway may be more complex than originally indicated. In-situ powder neutron diffraction (PND) $[2,3]$ revealed the possibility of a reaction pathway involving the formation of the lithium nitride hydride, $\mathrm{Li}_{4} \mathrm{NH}[4,5]$ from lithium nitride in addition to the hydrogenated phase, lithium imide, $\mathrm{Li}_{2} \mathrm{NH}$. At a low partial pressure of hydrogen, the formation of $\mathrm{LiH}$ appears to be suppressed, leading to the overall reaction shown in Equation (3). The dehydrogenation behaviour of $\mathrm{Li}_{4} \mathrm{NH}$ itself, however, remains essentially unknown and $\mathrm{Li}_{4} \mathrm{NH}$ is the only nitride hydride currently known in the $\mathrm{Li}-\mathrm{N}-\mathrm{H}$ system.

$$
2 \mathrm{Li}_{3} \mathrm{~N}+\mathrm{H}_{2} \rightarrow \mathrm{Li}_{4} \mathrm{NH}+\mathrm{Li}_{2} \mathrm{NH}
$$

Further, non-stoichiometric phases can be formed at $723 \mathrm{~K}$ from the reaction between the hydride and imide products in Equation (3). These complex non-stoichiometric phases thus contain $\mathrm{N}^{3-}, \mathrm{H}^{-}$and $(\mathrm{NH})^{2-}$ anions and form a solid solution [Equation (4)] [4]:

$$
(1-x) \mathrm{Li}_{4} \mathrm{NH}+x \mathrm{Li}_{2} \mathrm{NH} \rightarrow \mathrm{Li}_{4-2 x} \mathrm{~N}_{1-x} \mathrm{H}_{1-x}(\mathrm{NH})_{x}
$$

A full understanding of the structure and reactivity of $\mathrm{Li}_{4} \mathrm{NH}$ is thus required in order to determine its role in the $\mathrm{Li}-\mathrm{N}-\mathrm{H}$ system and the process of hydrogen uptake and release. One of the problems in developing such an understanding centres on the reliable synthesis of single phase $\mathrm{Li}_{4} \mathrm{NH}$. Preparation of the phase requires the solid state reaction of $\mathrm{Li}_{3} \mathrm{~N}$ and $\mathrm{LiH}$ at high temperature under strictly anaerobic conditions while preventing side reactions with container materials.

In this work we demonstrate how microwave synthesis of $\mathrm{Li}_{4} \mathrm{NH}$ using both commercial multi-mode and single-mode microwave (MW) cavities can provide a solution to this problem. The result is a reproducible route for the synthesis of phase-pure $\mathrm{Li}_{4} \mathrm{NH}$ over timescales orders of magnitude shorter than those required for conventional heating methods, which are less energy-efficient and more difficult to control. This facile synthesis approach has allowed us to produce bulk powders of $\mathrm{Li}_{4} \mathrm{NH}$ for a subsequent comprehensive study of structure, stability and reactivity. This synthesis method may well be extrapolated successfully to other hydrogen storage materials.

\section{Experimental Section}

\subsection{Synthesis of $L i_{4} N H$}

All manipulations were performed in an $\mathrm{N}_{2}$-filled glovebox ( $\left.5 \mathrm{ppm}_{2} ; 10 \mathrm{ppm} \mathrm{H}_{2} \mathrm{O}\right)$. Lithium nitride, $\mathrm{Li}_{3} \mathrm{~N}$ (Alfa Aesar, Heysham, Lancashire, UK, 300 mesh, 99.95\%; ca. $0.1 \mathrm{~g}$ ) and lithium hydride, LiH (Sigma Aldrich, Gillingham, UK, 30 mesh, 95\%) (1:1.1 molar ratio) were ground manually with an agate mortar and pestle, pressed into pellets $(13 \mathrm{~mm}$ internal diameter, $1-2 \mathrm{~mm}$ thickness) for $30 \mathrm{~min}$ using a hand press and placed in an $\mathrm{N}_{2}$-filled silica tube $(25 \mathrm{~cm} \times 8 \mathrm{~mm} \times 2 \mathrm{~mm})$ 
sealed with parafilm. The silica tube was transferred from the glove box and sealed under vacuum $\left(10^{-2} \mathrm{~m} \cdot\right.$ bar). Reactions were conducted in either a multi-mode microwave reactor (Panasonic 4697 NN-TS53W, Panasonic UK Ltd., West Berkshire, UK, 900 Wmax. output, $2.45 \mathrm{GHz}$ ) or a single-mode microwave reactor $\left(\right.$ CEM Discover ${ }^{\circledR}$, CEM corporation, Matthews, NC, USA, 300 Wmax. output, $2.45 \mathrm{GHz}$ ). The resultant products were collected in the glovebox.

\subsection{Characterization}

Powder X-ray diffraction (PXD) was conducted using a Bruker D8 diffractometer (Bruker Corporation, Billerica, MA, USA, $\mathrm{Cu} \mathrm{K \alpha}$ source) or a PANalytical X'Pert Pro MPD powder diffractometer $\left(\mathrm{Cu} \mathrm{K \alpha} \alpha_{1}\right.$ source $)$ in capillary mode. The air-sensitive samples were ground into fine powders and placed in $0.5 \mathrm{~mm}$ diameter sealed glass capillaries for data collection. Data were collected in the range $5^{\circ} \leq 2 \theta \leq 85^{\circ}$ using a $0.0168^{\circ} 2 \theta$ step size for $1 \mathrm{~h}$ for phase identification or $10^{\circ} \leq 2 \theta \leq 110^{\circ}$ for $12 \mathrm{~h}$ for structure refinement. PXD data were indexed and refined by least squares fitting using the CELREF software package [6]. Structural refinements were conducted via the Rietveld method using the GSAS and EXPGUI packages [7,8] The scale factor, zero point and background were refined in initial cycles, A shifted Chebyschev polynomial function (background function 1 in GSAS) was employed to model the background. The unit cell parameters, peak profile parameters and atomic parameters were refined subsequently. The peak shape was modelled using the pseudo-Voigt function (profile function 2 in GSAS). Constraints were applied to the thermal parameters of the $\mathrm{N}$ and $\mathrm{H}$ atoms within both the LT- and HT- $\mathrm{Li}_{4} \mathrm{NH}$ phases.

Simultaneous thermal analysis (thermogravimetric and differential thermal analysis; TG-DTA) was performed using a NETZSCH STA 409PC thermobalance coupled to a HIDEN HPR20 mass spectrometer (MS). Approximately $30 \mathrm{mg}$ of $\mathrm{Li}_{4} \mathrm{NH}$ was placed in an alumina pan and heated from ambient temperature to either $773 \mathrm{~K}$ or $873 \mathrm{~K}$ at $5 \mathrm{~K} \cdot \mathrm{min}^{-1}$ under a flow of Ar or $\mathrm{N}_{2}\left(60 \mathrm{~mL} \cdot \mathrm{min}^{-1}\right)$, respectively. The maximum temperature was held for $1 \mathrm{~h}$ before cooling $\left(5 \mathrm{~K} \cdot \mathrm{min}^{-1}\right)$. Simultaneously, mass spectra for nitrogen, hydrogen, ammonia and water were recorded during heating.

IR spectra were collected at room temperature (20 scans/sample, $8 \mathrm{~cm}^{-1}$ resolution) using a Shimadzu FTIR 8400S instrument with a Pike MIRacle ATR sampling accessory. Raman spectra were collected at room temperature using a Horiba LabRAM HR confocal microscope system (Horiba Itd., Kyoto, Japan) with a $532 \mathrm{~nm}$ laser, $1200 \mathrm{gr} \cdot \mathrm{mm}^{-1}$ grating and a Synapse CCD detector. A hole aperture of $50 \mu \mathrm{m}$ and a 25 times reduced laser intensity were used in order to minimise sample decomposition.

\section{Results and Discussion}

\section{1. $\mathrm{Li}_{4} \mathrm{NH}$ Synthesis Using a Multimode Microwave Reactor}

MW synthesis in a commercial multimode cavity (MMC) reactor offers faster processing (over times of the order of minutes), increased energy efficiency and lower cost [9] than conventional high temperature approaches. To date, MW heating experiments with solid-state hydrogen storage materials have been limited to the study of the dehydrogenation properties of a small number of alkali, alkaline-earth and transition metal hydrides and of the alkali metal borohydrides, $\mathrm{LiBH}_{4}, \mathrm{NaBH}_{4}$ and $\mathrm{KBH}_{4}$ [10-12]. Nevertheless, given the difficulties in mapping the microwave field distributions in 
MMCs, there are some drawbacks related to this synthetic approach such as variable reaction reproducibility and poor material homogeneity.

Table 1 shows representative experiments performed to ascertain the appropriate reaction conditions for the successful synthesis of $\mathrm{Li}_{4} \mathrm{NH}$ (samples 1-5). A schematic of the reaction set-up for the synthesis of the samples described in this section is shown in Figure 1. Several reaction parameters such as microwave power, reaction times, atmosphere and the use of graphite $(G)$ as an external microwave susceptor were considered. It should be noted that the reaction times in Table 1 were not continuous; each reaction was stopped at regular intervals ( $c a .1$ min steps) to allow for cooling in an attempt to avoid overheating of the silica reaction ampoule.

Figure 1. Reaction set-up using an multimode cavity (MMC) reactor.

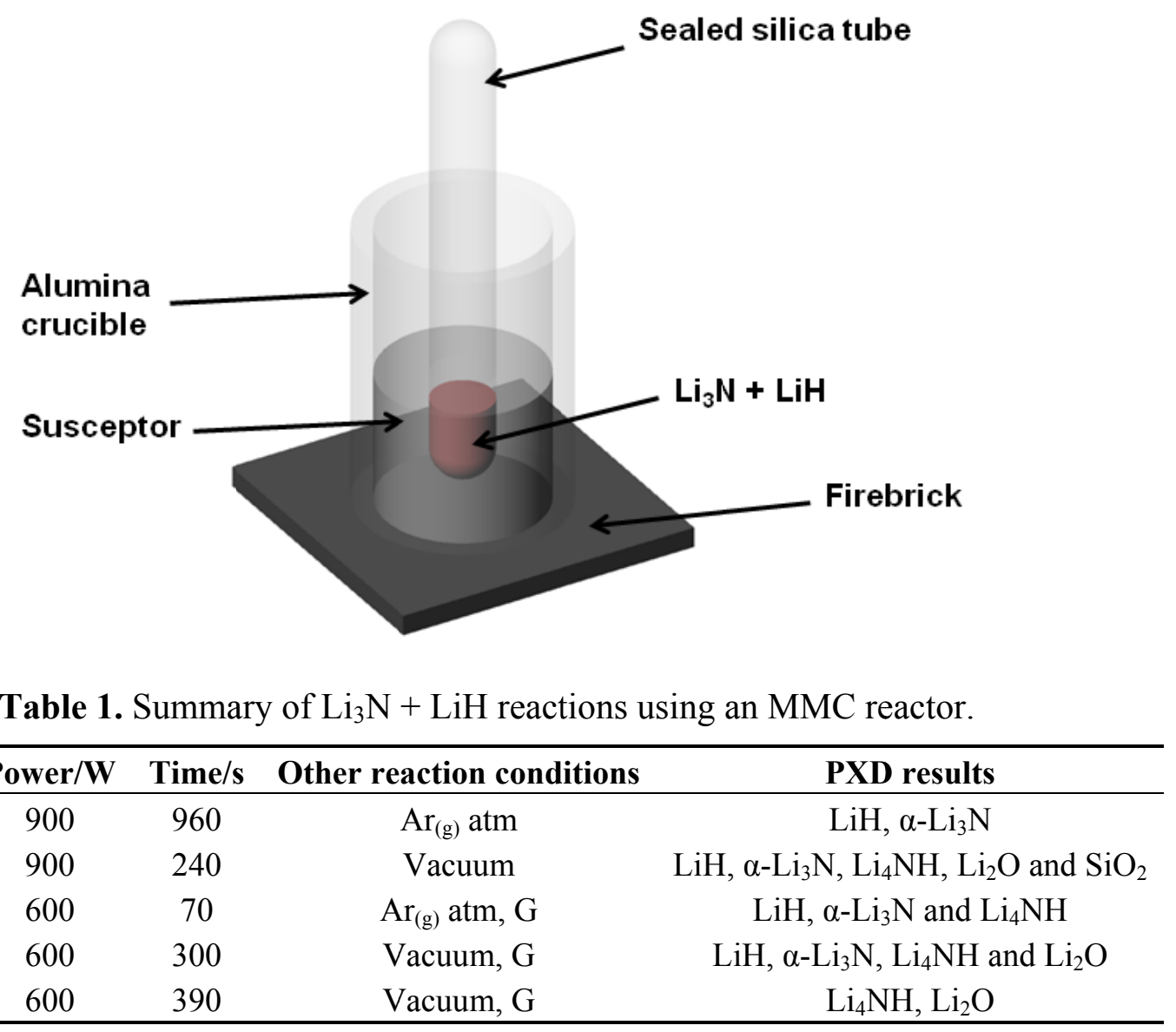

From these results it was shown that $\mathrm{Li}_{4} \mathrm{NH}$ could be synthesised under the conditions highlighted for sample 5. Figure 2 shows the PXD data obtained from sample 5; additional PXD of a partially reacted sample 2 was plotted for comparison. Silica peaks from the reaction vessel were also observed (marked with asterisks in the PXD pattern). For sample 5, the indexed cell parameters for $\mathrm{Li}_{4} \mathrm{NH}$ of $a=4.893(2) \AA$ and $c=9.936(8) \AA$ match well to those previously reported by Marx [Tetragonal space group $\left.I 4_{1} / a, a=4.8918(1) \AA, c=9.9321(3) \AA\right]$ [4]. Neither $\mathrm{N}-\mathrm{H}$ nor $\mathrm{O}-\mathrm{H}$ bands were observed in Raman spectra collected for sample 5 . The use of an external microwave susceptor, i.e., graphite, in these reactions appears essential in order to drive the reaction to completion. This can be rationalised in terms of the necessity to raise the reaction temperature to a point where the reactants exhibit a loss tangent $(\tan \delta)$ that is sufficient to couple effectively with microwaves [13]. In fact, it has been 
reported that graphite achieves a temperature of $1345 \mathrm{~K}$ in $c a .2 \mathrm{~min}$ of microwave irradiation [13]. Reactions performed under argon gas were not observed to proceed to completion, even in the presence of a graphite susceptor.

Figure 2. PXD data for the as-formed products obtained from MW irradiation in an MMC reactor (a) at $600 \mathrm{~W}$ for $390 \mathrm{~s}$ sample 5; and (b) at $900 \mathrm{~W}$ for $240 \mathrm{~s}$ sample 2. Indexed peaks correspond to the tetragonal $\mathrm{Li}_{4} \mathrm{NH}$ phase.

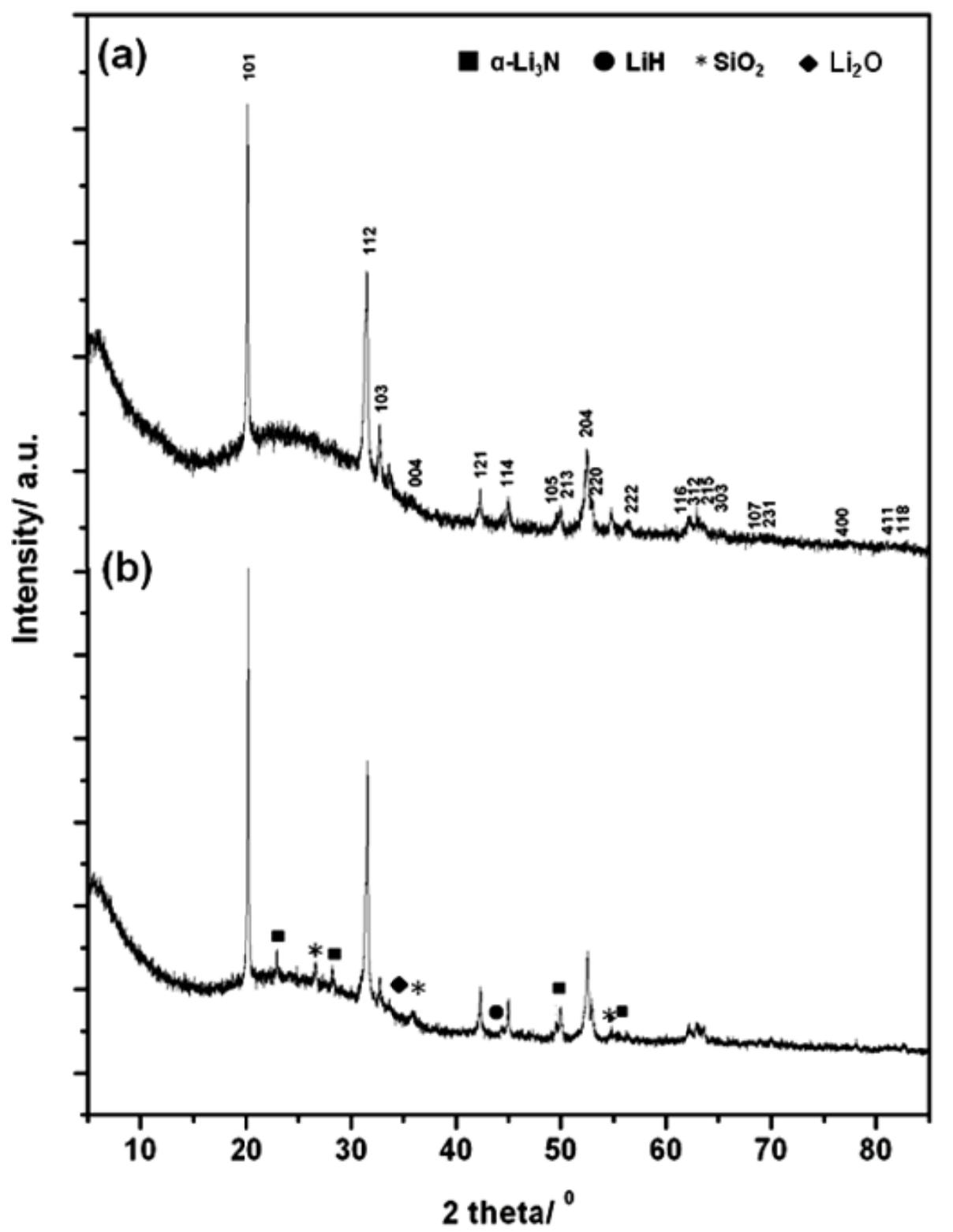

Despite successfully preparing high purity $\mathrm{Li}_{4} \mathrm{NH}$ using an $\mathrm{MMC}$, concerns over repeatability across experiments from uncertainties in the field distribution led us to consider the use of an single mode cavity (SMC) reactor to improve homogeneity, reproducibility and potentially further reduce reaction times. This cavity offers better control over reactions given the opportunity to accurately position the sample in a well-defined electric field [14]. Moreover, the use of an external susceptor in these reactions is avoided and therefore any risk of product contamination can be minimised. 


\subsection{Li ${ }_{4} N H$ Synthesis Using a Single Mode Microwave Reactor}

A summary of the reactions conducted in SMC system (Figure 3) is shown in Table 2. As for the MMC syntheses described in section 3.1, cooling intervals were introduced between irradiation periods to avoid melting of the silica reaction ampoule (i.e., melting point $2073 \mathrm{~K}$ ). Indeed, heating at $300 \mathrm{~W}$ for $t>240 \mathrm{~s}$ led to the destruction of the $\mathrm{SiO}_{2}$ reaction vessel. It is evident from PXD data collected for sample 8 that single phase $\mathrm{Li}_{4} \mathrm{NH}$ could be successfully synthesized at $300 \mathrm{~W}$ in $180 \mathrm{~s}$; no reflections from the starting materials $\alpha-\mathrm{Li}_{3} \mathrm{~N}$ and $\mathrm{LiH}$ were observed (Figure 4). The final product had the appearance of a yellow/beige pellet. Previously, $\mathrm{Li}_{4} \mathrm{NH}$ was synthesised from the reaction between $\mathrm{Li}_{3} \mathrm{~N}$ and $\mathrm{LiH}$ at $763 \mathrm{~K}$ for $6 \mathrm{~h}$ under $\mathrm{Ar}$ [4] and thus with the synthetic approach described here, reaction times could be reduced by a factor of 100 and performed without the need for an inert cover gas.

Table 2. Summary of $\mathrm{Li}_{3} \mathrm{~N}+\mathrm{LiH}$ reactions using a SMC reactor.

\begin{tabular}{ccccc}
\hline Reaction & Power/W & Time/s & Other reaction conditions & PXD results \\
\hline 6 & 150 & 270 & Vacuum & $\mathrm{LiH}, \alpha-\mathrm{Li}_{3} \mathrm{~N}$ and $\mathrm{Li}_{4} \mathrm{NH}$ \\
7 & 250 & 270 & Vacuum & $\mathrm{LiH}, \alpha-\mathrm{Li}_{3} \mathrm{~N}$ and $\mathrm{Li}_{4} \mathrm{NH}$ \\
8 & 300 & 180 & Vacuum & $\mathrm{Li}_{4} \mathrm{NH}$ \\
\hline
\end{tabular}

Figure 3. Reaction set-up using a SMC reactor.

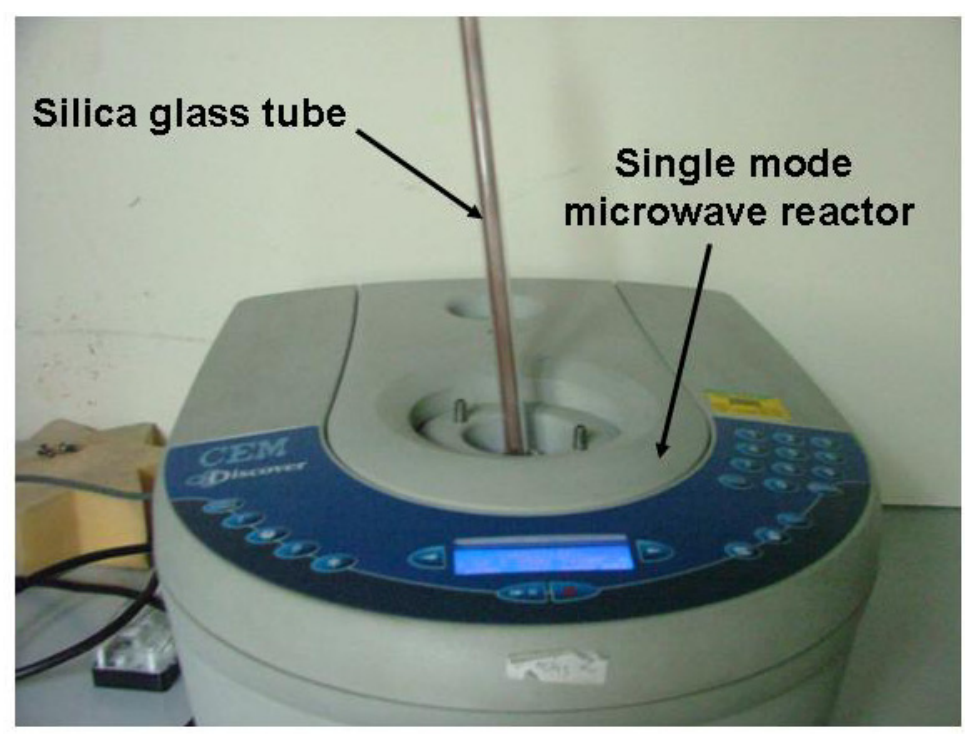

The MW synthesis of lithium nitride hydride is possible due to the ability of the starting materials to absorb microwave energy and convert this into heat (as reflected in the loss tangent, $\tan \delta$ ). The ability of $\mathrm{Li}_{3} \mathrm{~N}$ to produce heat in a microwave field may be attributed to its inherent fast ionic conductivity and semiconducting behavior $[15,16]$. In fact, it is well established that microwaves couple directly to charge carriers leading to extremely rapid reactions in many ionic conductors and semiconductors [17]. Conversely, $\mathrm{LiH}$ does not generate significant heat under a microwave field and, for example, no changes in temperature were observed when $\mathrm{LiH}$ was placed within SMC (400 W; 20 min) or MMC (500 W; $30 \mathrm{~min}$ ) reactors [7,9]. In fact, in these previous studies among $\mathrm{NaH}, \mathrm{MgH}_{2}, \mathrm{CaH}_{2}, \mathrm{TiH}_{2}$, $\mathrm{VH}_{0.81}, \mathrm{ZrH}_{2}$ and $\mathrm{LaH}_{2.48}$ only the transition metal and lanthanide hydrides showed a rapid increase in temperature, which even then only led to the desorption of a small percentage of hydrogen $(<0.5 \mathrm{wt} \%)$. 
Figure 4. PXD data for tetragonal $\mathrm{Li}_{4} \mathrm{NH}$ obtained in an $\mathrm{SMC}$ reactor at $300 \mathrm{~W}$ for $180 \mathrm{~s}$ under vacuum (sample 8).

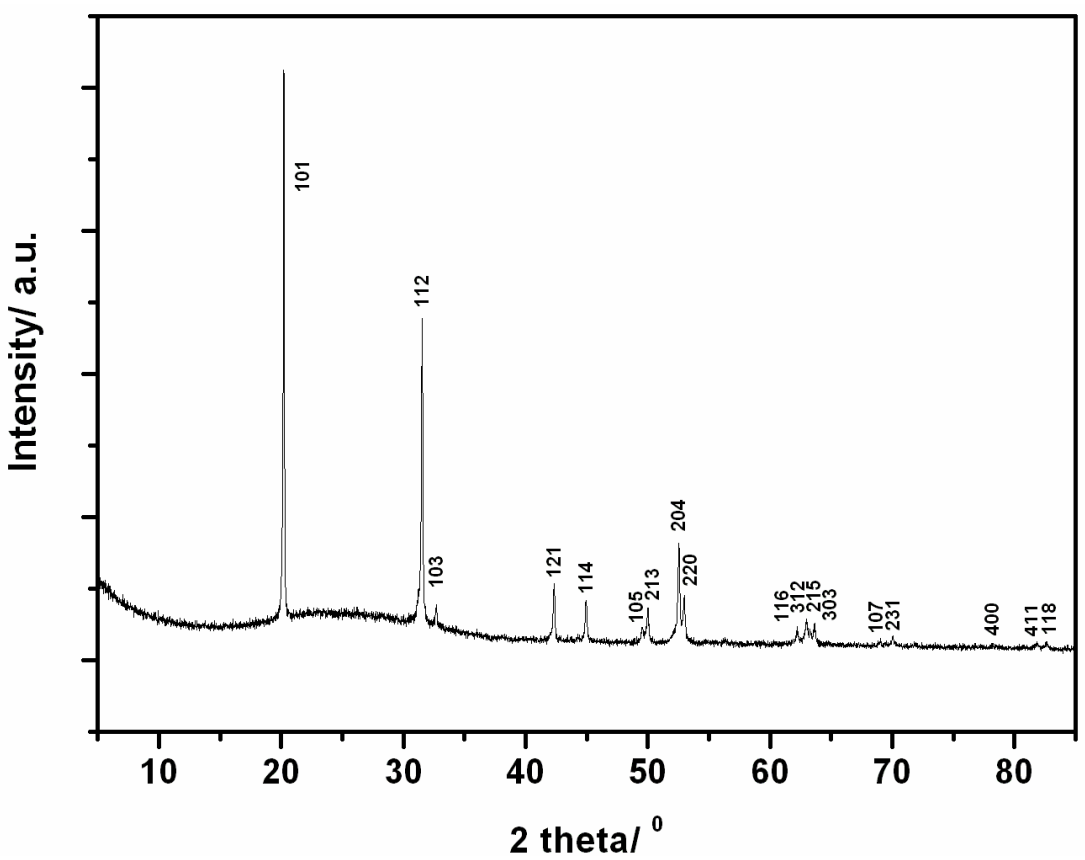

During the reactions described here (samples 1-8), a purple plasma was observed along the length of the silica reaction tube. The purple plasma was followed on most occasions by yellow/orange flashes (Additional Supplementary Information). The observation of these plasmas/flashes provides evidence for the high local temperatures achieved in the reaction vessel (i.e., Li evaporation occurs at $c a$. $1573 \mathrm{~K})[18]$.

\subsection{Thermal Stability of $\mathrm{Li}_{4} \mathrm{NH}$}

The thermal stability of the nitride hydride was investigated by TG-DTA under flowing argon. TG-DTA of sample 8 showed no evidence of mass change and hence decomposition or dehydrogenation when the sample was heated to $773 \mathrm{~K}$ (Figure 5a). Moreover, it was also evident from mass spectra collected simultaneously while heating that no hydrogen or other gases were evolved over the entire $\mathrm{m} / \mathrm{z}$ range $(1 \leq \mathrm{m} / \mathrm{z} \leq 200)$ (Figure $5 \mathrm{~b}$ ). These results corroborate previous investigations conducted to $698 \mathrm{~K}$ under argon [4]. Indexing of the PXD pattern from sample 8 following the TG-DTA experiment (Figure 5c) yielded cell parameters for $\mathrm{Li}_{4} \mathrm{NH}$ of $a=4.891(2) \AA$ and $c=9.9252(8) \AA$. These lattice parameters are within $2 \sigma$ of those obtained for this sample prior to

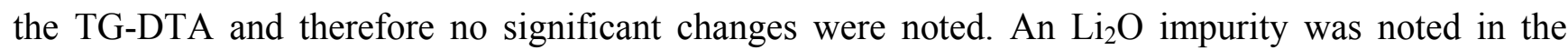
post-TG-DTA diffractogram and was attributed to the presence of moisture in the $\operatorname{Ar}_{(\mathrm{g})}$ and/or a reaction between a small amount of $\mathrm{Li}_{4} \mathrm{NH}$ and the alumina sample holder.

The DTA profile for sample 8 however reveals an interesting feature above $700 \mathrm{~K}$ with no corresponding simultaneous weight change. This endothermic peak at $770 \mathrm{~K}$ can thus be attributed to a structural phase transition in $\mathrm{Li}_{4} \mathrm{NH}$. An equivalent exothermic peak in the DTA was observed at $755.6 \mathrm{~K}$ on cooling, demonstrating that the phase transition is reversible (and as corroborated by PXD where the tetragonal $\mathrm{Li}_{4} \mathrm{NH}$ is observed as discussed above). 
Figure 5. (a) Thermogravimetric and differential thermal analysis (TG-DTA) profiles for sample 8 under $\operatorname{Ar}_{(\mathrm{g})}$. The sample was heated to $773 \mathrm{~K}$ at $5 \mathrm{~K} \mathrm{~min}^{-1}$ held for $1 \mathrm{~h}$ and cooled at $5 \mathrm{~K} \mathrm{~min}^{-1}$. TG, DTA and temperature curves are represented in black, blue and red respectively; (b) Mass spectra obtained under the conditions shown in (a). $\mathrm{NH}_{3(\mathrm{~g})}, \mathrm{N}_{2(\mathrm{~g})}$, $\mathrm{H}_{2(\mathrm{~g})}$ and $\mathrm{H}_{2} \mathrm{O}$ were monitored; and (c) PXD pattern showing the experimental data for sample 8 after heating and cooling under $\mathrm{Ar}$. The open squares denote a $\mathrm{Li}_{2} \mathrm{O}$ minor impurity phase.

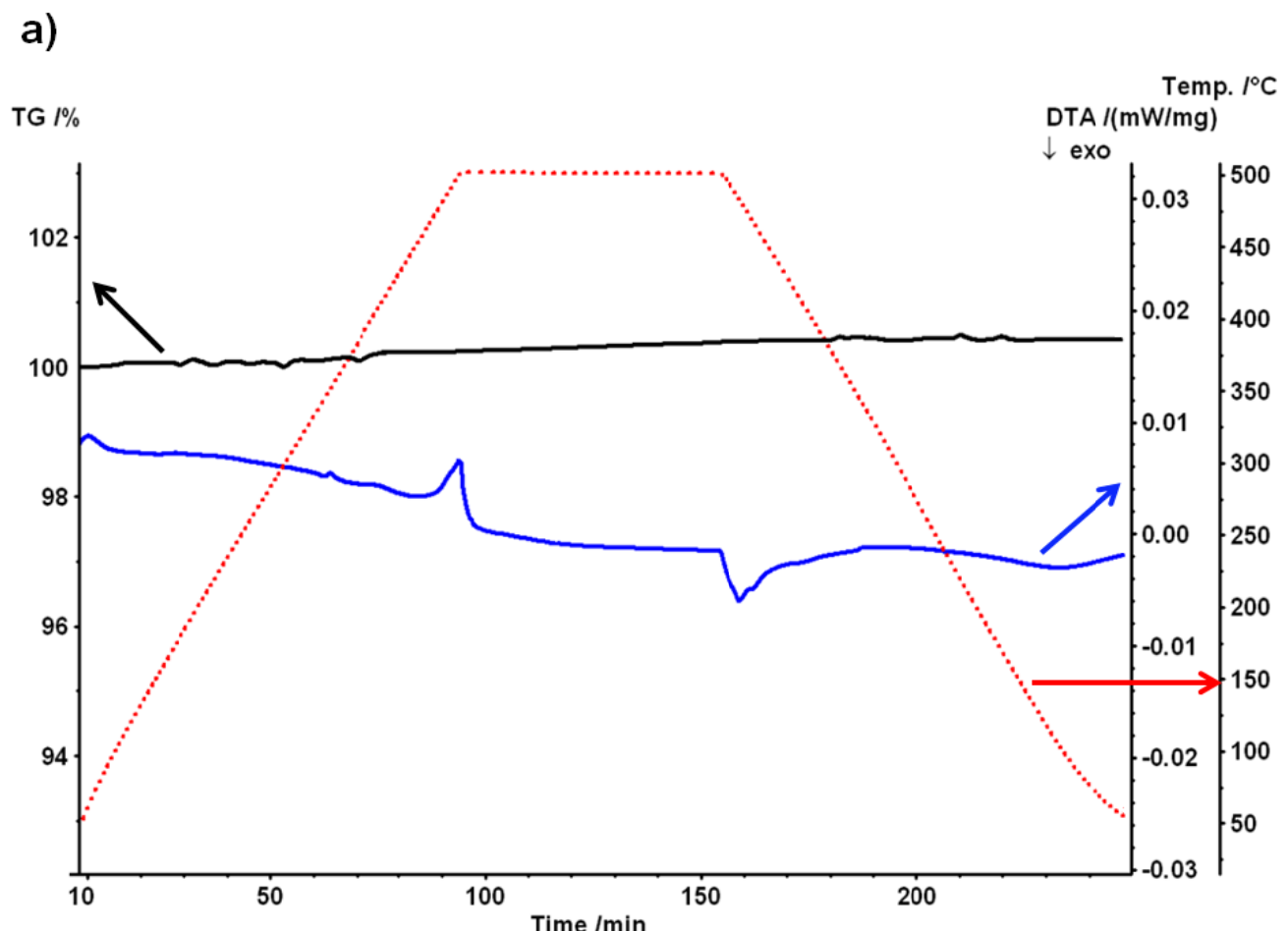

b)

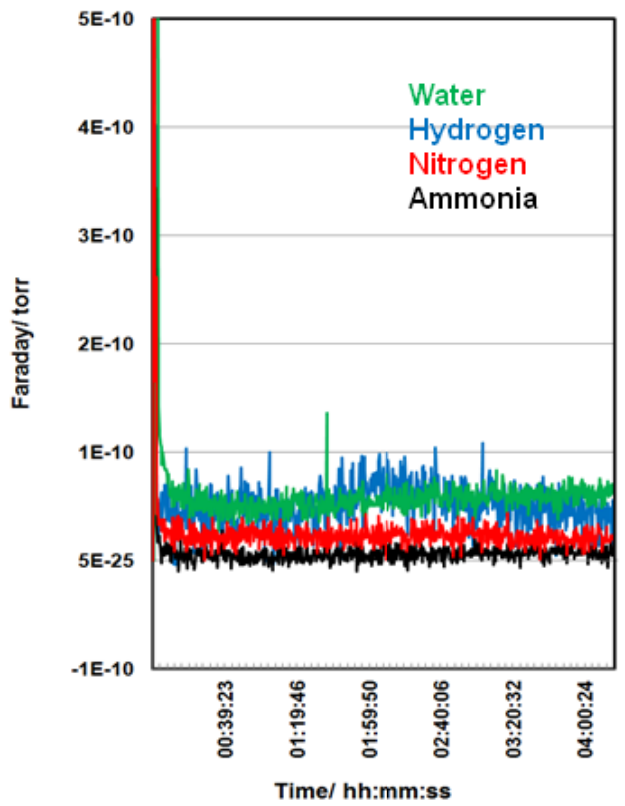

c)

\author{
(1)
}


In light of the evidence for a high temperature phase transition from the TG-DTA data, attempts were made to isolate the high-temperature $(\mathrm{HT}) \mathrm{Li}_{4} \mathrm{NH}$ phase by heating as-prepared $\mathrm{Li}_{4} \mathrm{NH}$ (sample 8 ) to $798 \mathrm{~K}$ at $5 \mathrm{~K} \mathrm{~min}^{-1}$ under flowing argon using a conventional furnace and quenching in liquid nitrogen. Figure 6 shows the PXD pattern of the reaction products collected after quenching (sample 9). The diffractogram comprises reflections for the tetragonal low temperature (LT) phase and $\mathrm{Li}_{2} \mathrm{O}$ but is notable for the appearance of a small number of new peaks corresponding to an HT-phase. The reflections for the HT- $\mathrm{Li}_{4} \mathrm{NH}$ phase could be indexed to a cube with $a=4.915(1) \AA$. The presence of $\mathrm{Li}_{2} \mathrm{O}$ in the reaction products is attributed to a possible reaction between $\mathrm{Li}_{4} \mathrm{NH}$ and the $\mathrm{SiO}_{2}$ reaction tube. Hence, it is quite likely that the unknown peaks observed in the powder pattern for sample 9 might correspond to $\mathrm{Li}-\mathrm{Si}-(\mathrm{N}-\mathrm{O})$ impurities from a side reaction with the reaction ampoule. Raman spectra collected for sample 9 showed the complete absence of either $\mathrm{N}-\mathrm{H}$ or $\mathrm{O}-\mathrm{H}$ bands.

Figure 6. PXD pattern of sample 8 (a) after quenching $\mathrm{Li}_{4} \mathrm{NH}$ from high temperature (to form sample 9); and (b) prior to heating.

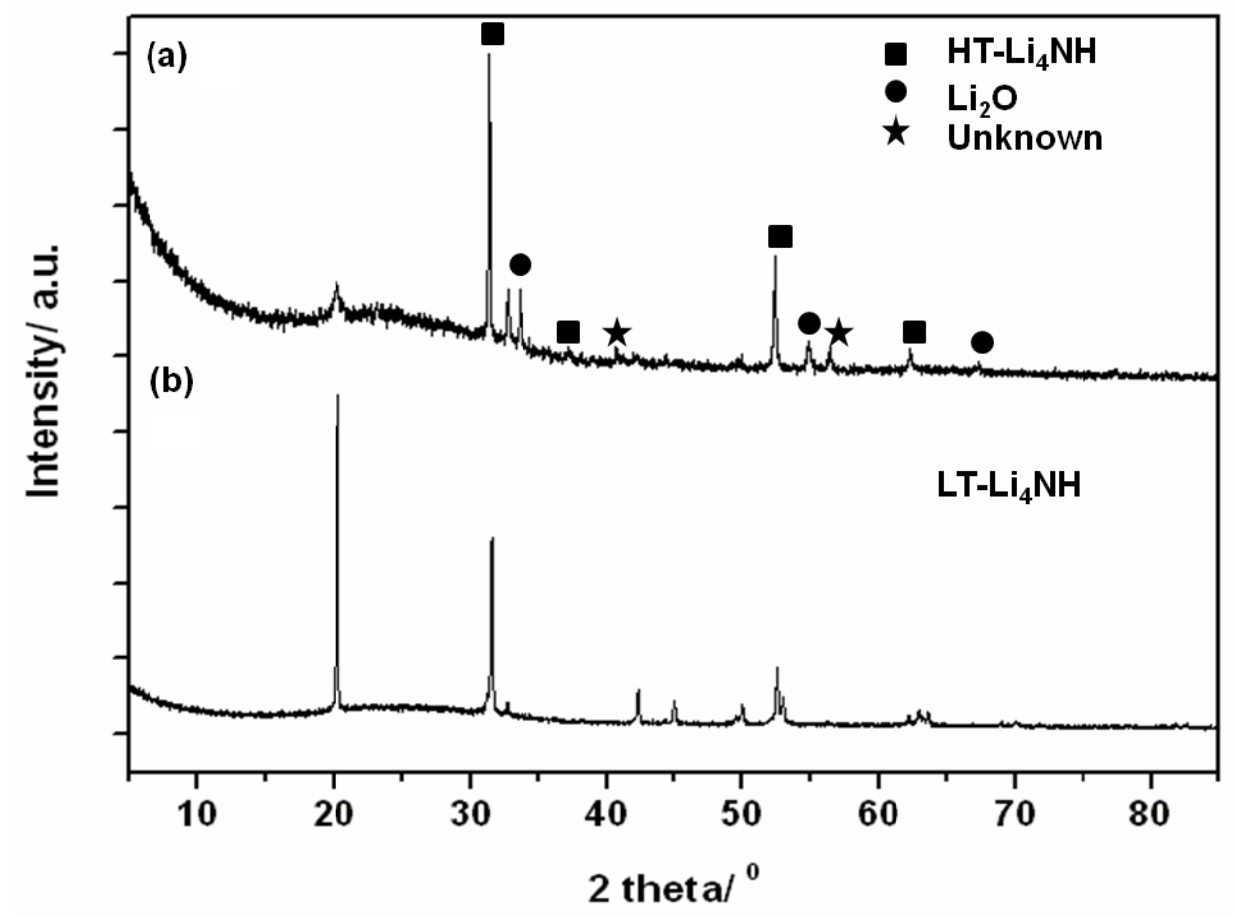

\subsection{Structure Determination}

Structure refinements performed against PXD data were conducted for sample 8. Selected Rietveld refinement data collected at room temperature are displayed in Table 3 and additional results are included in the Supplementary Information (Tables S1 and S2). Although a satisfactory fit for the data could be obtained using a single phase tetragonal model for $\mathrm{LT}-\mathrm{Li}_{4} \mathrm{NH}$, a marked improvement in the residuals was achieved when including the second HT-phase identified by the quenching experiments (see above). Traces of silica (assumed to originate from the reaction ampoule) were also found in the diffraction profile of sample 8 . The observed-calculated-difference (OCD) profile plot is shown in Figure 7. 
The presence of the HT-phase in sample 8 can be rationalised by the relatively fast cooling rate from the SMC MW reaction (as compared to conventional heating), which allows some of the kinetically stable $\mathrm{HT}-\mathrm{Li}_{4} \mathrm{NH}$ phase to remain in the sample at room temperature.

Table 3. Selected Rietveld refinement data from the lab X-ray refinement of sample 8 at $298 \mathrm{~K}$.

\begin{tabular}{ccc}
\hline Empirical formula & LT-Li $_{4} \mathbf{N H}$ & HT-Li $_{4} \mathbf{N H}$ \\
\hline Collection temperature/K & 298 & 298 \\
Crystal system & Tetragonal & Cubic \\
Space group & $I 4_{1} / a$ & $F m \overline{3} m$ \\
Lattice parameters/ $\AA$ & $a=4.8864(1)$ & $a=4.9462(3)$ \\
$V / \AA^{3}$ & $c=9.9183(2)$ & \\
$Z$ & $236.82(1)$ & $121.01(2)$ \\
Unit cell formula weight, $M_{\mathrm{w}}$ & 4 & 4 \\
Density/g cm & 171.116 & 85.558 \\
Phase fraction/wt\% & 1.200 & 1.174 \\
No. of observations, parameters & $98.1(5)$ & $1.8(5)$ \\
$R_{\mathrm{wp}}, R_{\mathrm{p}}$ & \multicolumn{2}{c}{$12,117,35$} \\
$\chi^{2}$ & \multicolumn{2}{c}{$1.0373,0.0273$} \\
\hline
\end{tabular}

Figure 7. Observed-calculated-difference (OCD) profile plot from the room temperature Rietveld refinement for sample 8. Observed data are shown in red, calculated data are shown in green and the difference between the two profiles is shown in pink. Black tickmarks correspond to tetragonal $\mathrm{Li}_{4} \mathrm{NH}$, red tickmarks correspond to cubic $\mathrm{Li}_{4} \mathrm{NH}$ and blue tickmarks correspond to $\mathrm{SiO}_{2}$.

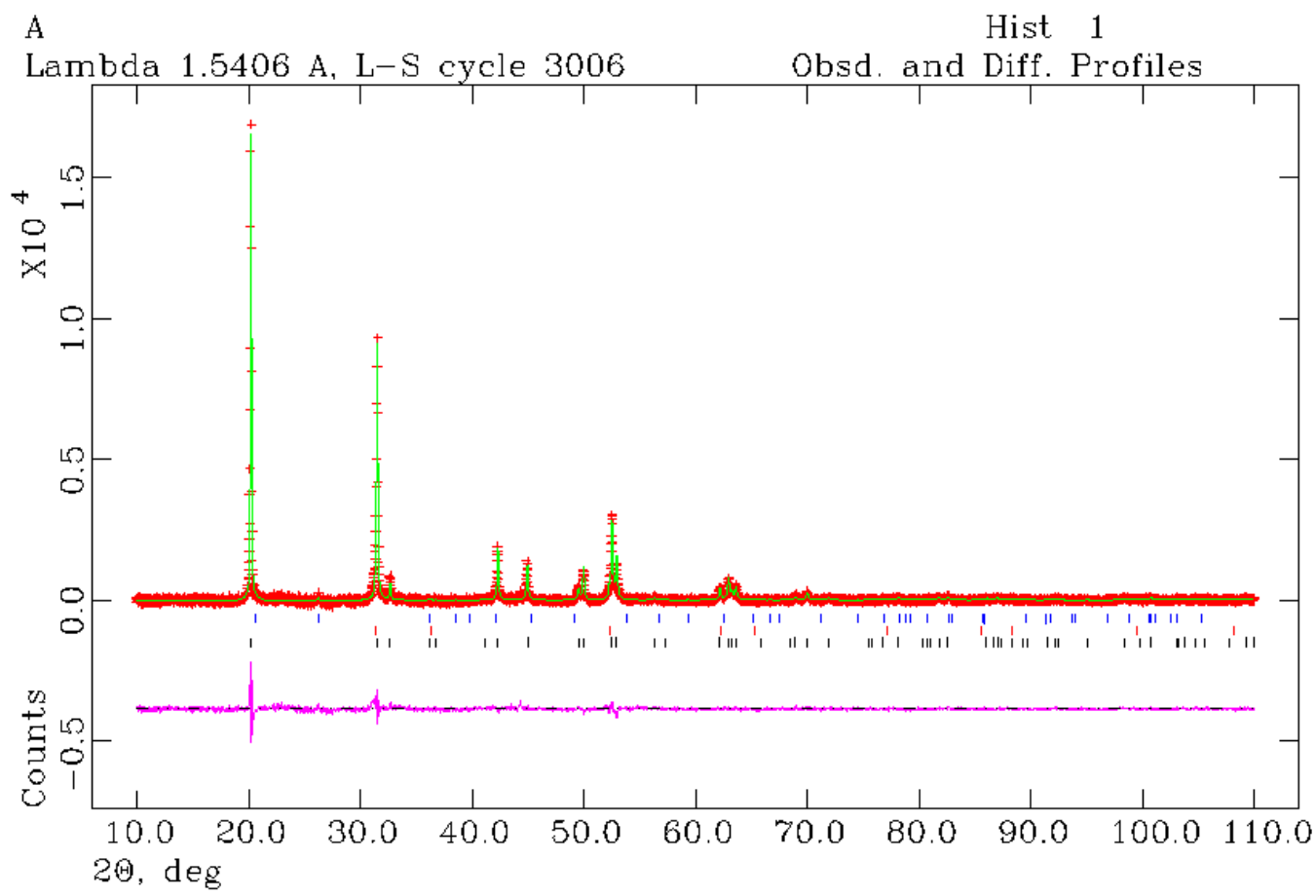


The LT-Li ${ }_{4} \mathrm{NH}$ phase was modeled in tetragonal space group $I 4_{1} / a$ with lattice parameters $a=4.8864(1) \AA$ and $c=9.9183(2) \AA$ (Figure 8a) and corresponds to the structure originally reported by Marx and re-determined by Niewa et al. [4,5].from PXD and PND data and single crystal X-ray diffraction data respectively. Initial attempts were made to fit $\mathrm{HT}-\mathrm{Li}_{4} \mathrm{NH}$ in tetragonal space groups but following the elucidation of the second phase from the quenching experiments described in Section 3.3, a better structural model was chosen. The structure of HT-Li ${ }_{4} \mathrm{NH}$ was refined in the cubic space group $F m \overline{3} m$ with $a=4.9462(3) \AA$ (Figure $8 b$ ) using a model based on a modified $\mathrm{Li}_{2} \mathrm{NH}$-type anti-fluorite structure in which $\mathrm{N}^{3-}$ and $\mathrm{H}^{-}$equally occupy the $4 a$ site occupied by the imido $\mathrm{N}$ atom in $\mathrm{Li}_{2} \mathrm{NH}$ [19]. The structure thus corresponds to a regular $\mathrm{Li}_{2}(\mathrm{~N}, \mathrm{H})$ cube derived from the tetragonal LT-Li 4 NH structure where $a_{\text {cubic }} \sim a_{\text {tetragonal }}$ and $a_{\text {cubic }} \sim c_{\text {tetragonal }} / 2$.

Figure 8. Crystal structures of (a) the LT-Li ${ }_{4} \mathrm{NH}$ phase (space group $I 4_{1} / a$ ), where Li atoms are represented in pink; N1/H1 are represented in orange; and N2/H2 atoms are represented in blue; and (b) the $\mathrm{HT}-\mathrm{Li}_{4} \mathrm{NH}$ phase (space group $F m \overline{3} \mathrm{~m}$ ). Lithium atoms are represented in pink and $\mathrm{N} / \mathrm{H}$ atoms are represented in blue. Polyhedra showing the coordination environment of the $\mathrm{Li}$ and $\mathrm{N} / \mathrm{H}$ atoms are represented in yellow.

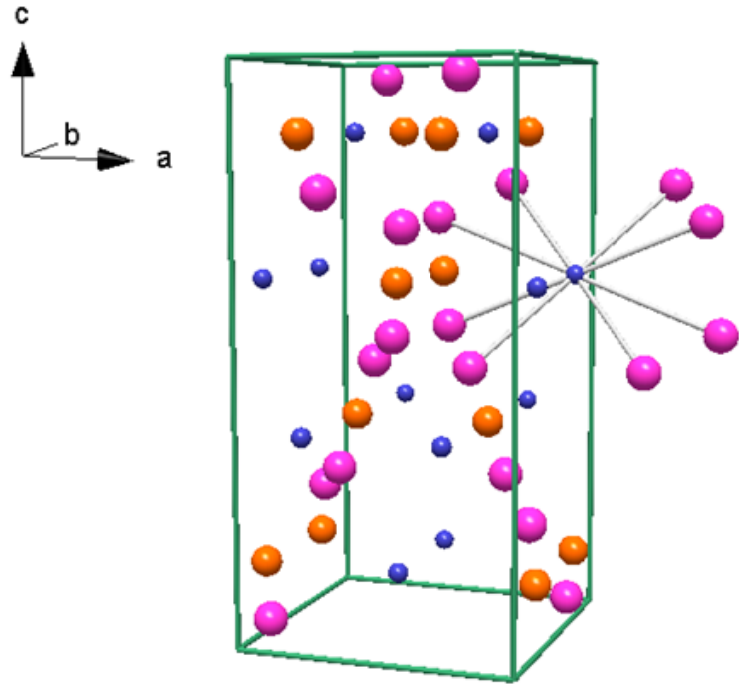

(a)

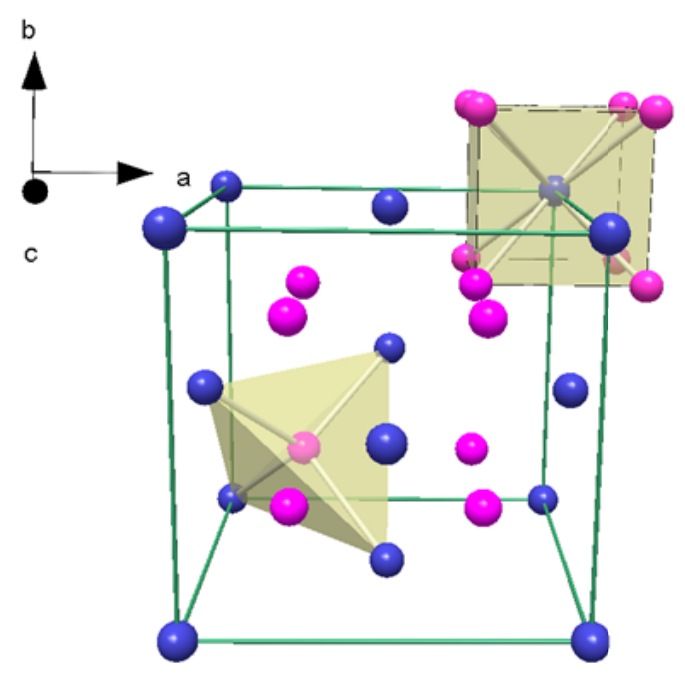

(b)

Atomic positions and isotropic thermal parameters for each $\mathrm{Li}_{4} \mathrm{NH}$ phase are presented in Tables 4 and 5. Given that PXD is not able to locate hydride accurately, the occupancies of the $\mathrm{N}^{3-}$ and $\mathrm{H}^{-}$ anions in the LT- $\mathrm{Li}_{4} \mathrm{NH}$ phase were fixed at values reported by Marx [4]. Attempts to fix the site occupancies at alternative values representing different distributions of anions led to poorer quality fits. The LT-phase therefore exhibits anion ordering with the $4 a$ site predominantly occupied by $\mathrm{N}^{3-}$ (at $95 \%$ ) and the $4 b$ site similarly almost fully occupied by $\mathrm{H}^{-}$. The cubic HT-Li $\mathrm{NHH}_{4}$ phase displays a disordered $\mathrm{N}^{3-} / \mathrm{H}^{-}$anion distribution over the $4 a$ site. The occupancies for the $\mathrm{N}^{3-}$ and $\mathrm{H}^{-}$atoms in the HT-Li ${ }_{4} \mathrm{NH}$ phase were both fixed to $50 \%$ in order to achieve charge balance. Given the structural relationship between the LT- and $\mathrm{HT}-\mathrm{Li}_{4} \mathrm{NH}$ phases, it is not surprising that the coordination environments around the cations and anions in each phase are very similar. Whereas in the LTstructure the essentially fully ordered $\mathrm{N}^{3-}$ and $\mathrm{H}^{-}$anions are in a distorted cubic coordination with $\mathrm{Li}^{+}$ (with distances ranging between 2.044(2)-2.082(2) $\AA$ and 1.949(2)-2.556(3) $\AA$ respectively), in the 
HT-structure fully disordered $\mathrm{N}^{3-} / \mathrm{H}^{-}$anions are in a regular cubic coordination, with an $\mathrm{Li}-\left(\mathrm{N}^{3-} / \mathrm{H}^{-}\right.$ distance of 2.1418(1) $\AA$ (Supplementary Information; Table S1). Li atoms are tetrahedrally coordinated to N/H atoms in the HT-phase. There are also strong similarities between the anti-fluorite structures of HT- $\mathrm{Li}_{4} \mathrm{NH}\left(\mathrm{Li}_{2} \mathrm{~N}_{0.5} \mathrm{H}_{0.5}\right)$ and $\mathrm{Li}_{2} \mathrm{NH}\left(\mathrm{Li}_{2}(\mathrm{NH})\right)$. The $\mathrm{Li}-\mathrm{N}^{3-} / \mathrm{H}^{-}$bond lengths are shorter than the lithium-imido Li-N distances reported by Balogh et al. [19] in $\mathrm{Li}_{2} \mathrm{NH}$. (2.205 $\AA$ ).

Nitride hydrides are relatively rare but $\mathrm{N}^{3-} / \mathrm{H}^{-}$anion ordering similar to that in the LT-Li ${ }_{4} \mathrm{NH}$ phase has also been observed in alkaline earth metal nitride hydrides such as $\mathrm{Ca}_{2} \mathrm{NH}(\mathrm{D})$ (cubic space group $F d \overline{3} m$ ) [20,21], $\mathrm{Ba}_{2} \mathrm{NH}(\mathrm{D})$ and $\mathrm{Sr}_{2} \mathrm{NH}$ (both hexagonal space group $R \overline{3} m$ ) [22,23]. Although there are no previously reported examples of complete $\mathrm{N}^{3-} / \mathrm{H}^{-}$disorder in the solid state, the anion disorder in $\mathrm{HT}-\mathrm{Li}_{4} \mathrm{NH}$ is paralleled by the $\mathrm{N}^{3-} / \mathrm{F}^{-}$distribution in nitride fluorides such as $\mathrm{Ba}_{2} \mathrm{NF}[24,25]$. Further studies on deuterated $\mathrm{LT}-\mathrm{Li}_{4} \mathrm{NH}$ and $\mathrm{HT}-\mathrm{Li}_{4} \mathrm{NH}$ using powder neutron diffraction will be performed to elucidate the crystal structures more fully (i.e., determine accurate hydrogen (deuterium) occupancies and anisotropic thermal parameters).

Table 4. Atom positions and isotropic thermal parameters generated by Rietveld refinement against lab X-ray data for $\mathrm{LT}-\mathrm{Li}_{4} \mathrm{NH}$ (sample 8) at $298 \mathrm{~K}$.

\begin{tabular}{cccccc}
\hline Atom & N1 & H1 & N2 & H2 & Li1 \\
\hline Site & $4 a$ & $4 a$ & $4 b$ & $4 b$ & $16 f$ \\
$\mathrm{x}$ & 0 & 0 & 0 & 0 & $0.1959(5)$ \\
$\mathrm{y}$ & 0.25 & 0.25 & 0.25 & 0.25 & $0.4618(4)$ \\
$\mathrm{z}$ & 0.125 & 0.125 & 0.625 & 0.625 & $0.2794(2)$ \\
$100 \times \mathrm{U}_{\text {iso }} / \AA^{2}$ & $3.9(1)$ & $3.9(1)$ & $3.1(4)$ & $3.1(4)$ & $6.93(9)$ \\
Site occupancy & 0.95 & 0.05 & 0.05 & 0.95 & 1.00 \\
\hline
\end{tabular}

Table 5. Atom positions used for Rietveld refinement against PXD data for $\mathrm{HT}-\mathrm{Li}_{4} \mathrm{NH}$ (in sample 8) at $298 \mathrm{~K}$. (Thermal parameters were fixed for this minority phase).

\begin{tabular}{cccc}
\hline Atom & Li1 & N1 & H1 \\
\hline Site & $8 c$ & $4 a$ & $4 a$ \\
$\mathrm{x}$ & 0.25 & 0 & 0 \\
$\mathrm{y}$ & 0.25 & 0 & 0 \\
$\mathrm{z}$ & 0.25 & 0 & 0 \\
$100 \times \mathrm{U}_{\text {iso }} / \AA^{2}$ & 2.5 & 2.5 & 2.5 \\
Occupancy & 1.00 & 0.50 & 0.50 \\
\hline
\end{tabular}

\subsection{Reactivity of $\mathrm{Li}_{4} \mathrm{NH}$ with Air and Nitrogen}

\subsection{1. $\mathrm{Li}_{4} \mathrm{NH}$ in Air}

To determine the reactivity of $\mathrm{Li}_{4} \mathrm{NH}$ in air, a freshly made sample was exposed to the ambient atmosphere for different times and the as-formed products were analysed by PXD (Figure 9). After $4 \mathrm{~h}$ of air exposure, $\mathrm{Li}_{4} \mathrm{NH}$ had completely reacted to form crystalline phases of $\mathrm{Li}_{2} \mathrm{CO}_{3}, \mathrm{LiOH} \cdot \mathrm{H}_{2} \mathrm{O}$ and $\mathrm{LiOH}$. Prolonged (e.g., $24 \mathrm{~h}$ ) exposure of $\mathrm{Li}_{4} \mathrm{NH}$ to air led predominantly to $\mathrm{Li}_{2} \mathrm{CO}_{3}$ with some $\mathrm{Li}_{2} \mathrm{OH} \cdot \mathrm{H}_{2} \mathrm{O}$ still present. Given this experimental evidence and by analogy to $\mathrm{Li}_{3} \mathrm{~N}$ [26], the hydrolysis 
of the nitride hydride is likely to proceed via $\mathrm{LiOH}$ formation (with evolution of ammonia and hydrogen; Equation 5) followed by further hydration to obtain the monohydrated hydroxide [Equation (6)]:

$$
\begin{array}{ll}
\mathrm{Li}_{4} \mathrm{NH}+4 \mathrm{H}_{2} \mathrm{O} \rightarrow 4 \mathrm{LiOH}+\mathrm{NH}_{3}+\mathrm{H}_{2} & \Delta \mathrm{H}_{298 \mathrm{~K}}=-793.117 \mathrm{~kJ} \cdot \mathrm{mol}^{-1}[27] \\
\mathrm{LiOH}+\mathrm{H}_{2} \mathrm{O} \rightarrow \mathrm{LiOH} \cdot \mathrm{H}_{2} \mathrm{O} & \Delta \mathrm{H}_{298 \mathrm{~K}}=-60.757 \mathrm{~kJ} \cdot \mathrm{mol}^{-1}[16]
\end{array}
$$

Although there is the possibility that both $\mathrm{LiOH}$ and $\mathrm{LiOH} \cdot \mathrm{H}_{2} \mathrm{O}$ react with $\mathrm{CO}_{2}$ to form lithium carbonate [Equations (7) and (8) respectively], from the calculated reaction enthalpies we can establish that the former reaction is more favourable. In fact, it was not possible to identify any $\mathrm{LiOH}$ in the PXD pattern obtained after $24 \mathrm{~h}$ [although as previously stated, this also reacts with air moisture from the air to form the monohydrated LiOH (Equation 6)].

$$
\begin{array}{lc}
2 \mathrm{LiOH}+\mathrm{CO}_{2} \rightarrow \mathrm{Li}_{2} \mathrm{CO}_{3}+\mathrm{H}_{2} \mathrm{O} & \Delta \mathrm{H}_{298 \mathrm{~K}}=-89.487 \mathrm{~kJ} \mathrm{~kJ} \cdot \mathrm{mol}^{-1}[16] \\
2 \mathrm{LiOH} \cdot \mathrm{H}_{2} \mathrm{O}+\mathrm{CO}_{2} \rightarrow 3 \mathrm{H}_{2} \mathrm{O}+\mathrm{Li}_{2} \mathrm{CO}_{3} & \Delta \mathrm{H}_{298 \mathrm{~K}}=+32.027 \mathrm{~kJ} \cdot \mathrm{mol}^{-1}[16]
\end{array}
$$

Figure 9. PXD patterns of the products after $\mathrm{Li}_{4} \mathrm{NH}$ air exposure for (a) $24 \mathrm{~h}$; and (b) $4 \mathrm{~h}$.

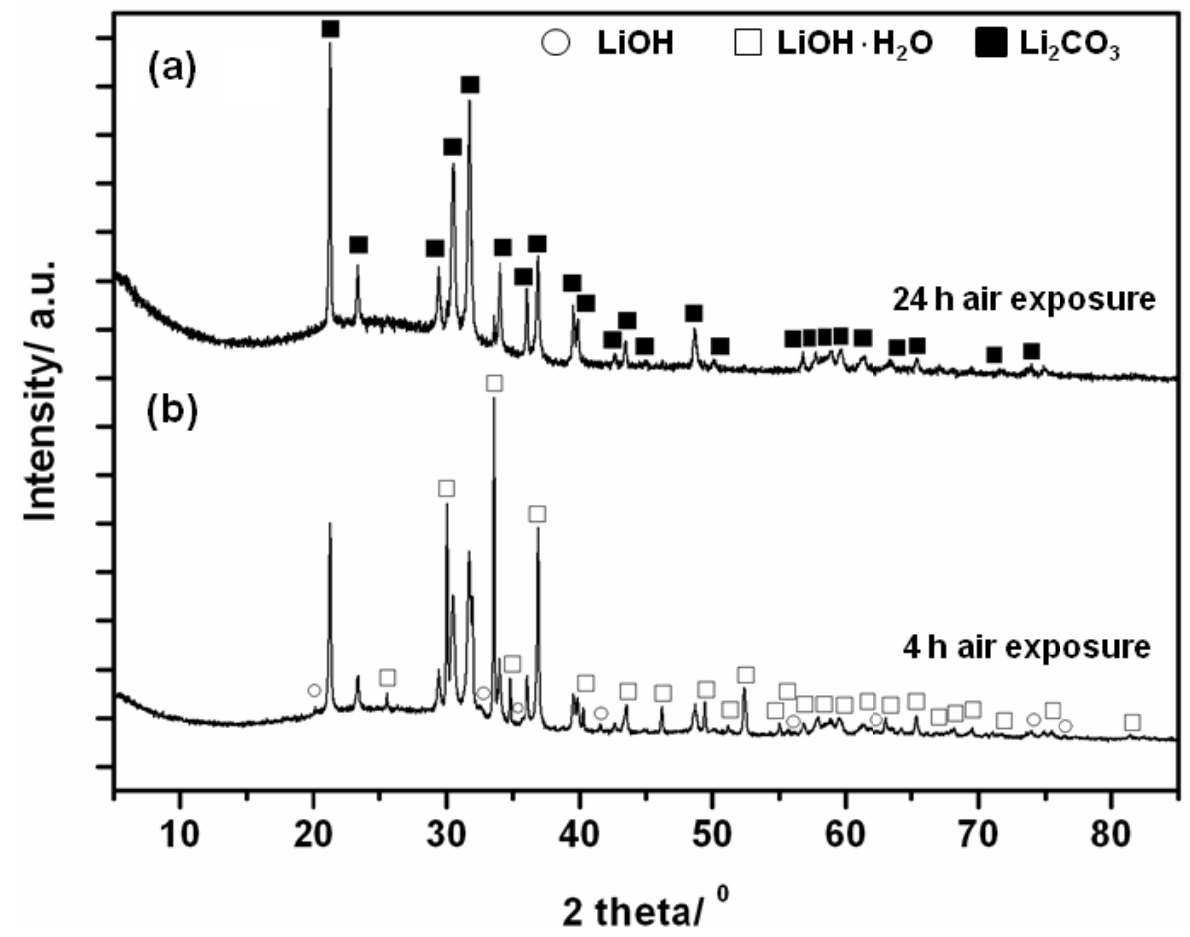

\subsection{2. $\mathrm{Li}_{4} \mathrm{NH}$ under $\mathrm{N}_{2 \text { (gas) }}$ at Variable Temperature}

The TG-DTA profile of the reaction between $\mathrm{Li}_{4} \mathrm{NH}$ and $\mathrm{N}_{2(\mathrm{~g})}$ on heating to $873 \mathrm{~K}$ and cooling (both at $5 \mathrm{~K} \cdot \mathrm{min}^{-1}$ ) (Figure 10) shows an increase in weight (with onset at ca. $573 \mathrm{~K}$ ) that stabilises by $873 \mathrm{~K}$. Overall, a weight gain of $19.2 \mathrm{wt} \%$ was achieved over the course of the reaction. Mass spectra taken during the analysis did not show any gas evolution (Supplementary Information, Figure S1). PXD of the post-STA products revealed the presence of $\alpha-\mathrm{Li}_{3} \mathrm{~N}$ and cubic- $\mathrm{Li}_{2} \mathrm{NH}$, as the main products with no evidence of remaining nitride hydride starting material. Some evidence of $\mathrm{LiOH}$ and $\mathrm{Li}_{2} \mathrm{O}$ was also found in the PXD pattern. By contrast to spectra for $\mathrm{Li}_{4} \mathrm{NH}$, further characterisation using Raman 
spectroscopy showed two characteristic bands at $3162.6 \mathrm{~cm}^{-1}$ and $3227.8 \mathrm{~cm}^{-1}$ (Figure 10, inset). These bands correspond to the symmetric and asymmetric $\mathrm{N}-\mathrm{H}$ vibrational modes in $\mathrm{Li}_{2} \mathrm{NH}[28,29]$.

The mass change in the TGA profile can therefore be rationalised in terms of the reaction:

$$
3 \mathrm{Li}_{4} \mathrm{NH}+\mathrm{N}_{2} \rightarrow 2 \mathrm{Li}_{3} \mathrm{~N}+3 \mathrm{Li}_{2} \mathrm{NH}
$$

The formation of lithium nitride and lithium imide from the nitride hydride corresponds to a theoretical gain of $21.8 \mathrm{wt} \%$, which is in reasonable agreement with the experimental values obtained by thermal analysis (given also the observation of $\mathrm{LiOH}$ and $\mathrm{Li}_{2} \mathrm{O}$ as noted above). By contrast to previous suggestions, TG-DTA would thus indicate that the reaction of $\mathrm{Li}_{4} \mathrm{NH}$ requires a temperature in excess of $823 \mathrm{~K}$ to reach completion [4].

Figure 10. (a) TG-DTA plot of $\mathrm{Li}_{4} \mathrm{NH}$ heated to $873 \mathrm{~K}$ and cooled at $5 \mathrm{~K} \cdot \mathrm{min}^{-1}$ under an $\mathrm{N}_{2}$ flow; and (b) PXD pattern of the reaction products obtained after thermal treatment under nitrogen; Inset: Raman spectra of the reaction products in the range $2500-4000 \mathrm{~cm}^{-1}$, showing the characteristic $\mathrm{N}-\mathrm{H}$ bands from $\mathrm{Li}_{2} \mathrm{NH}$.

a)
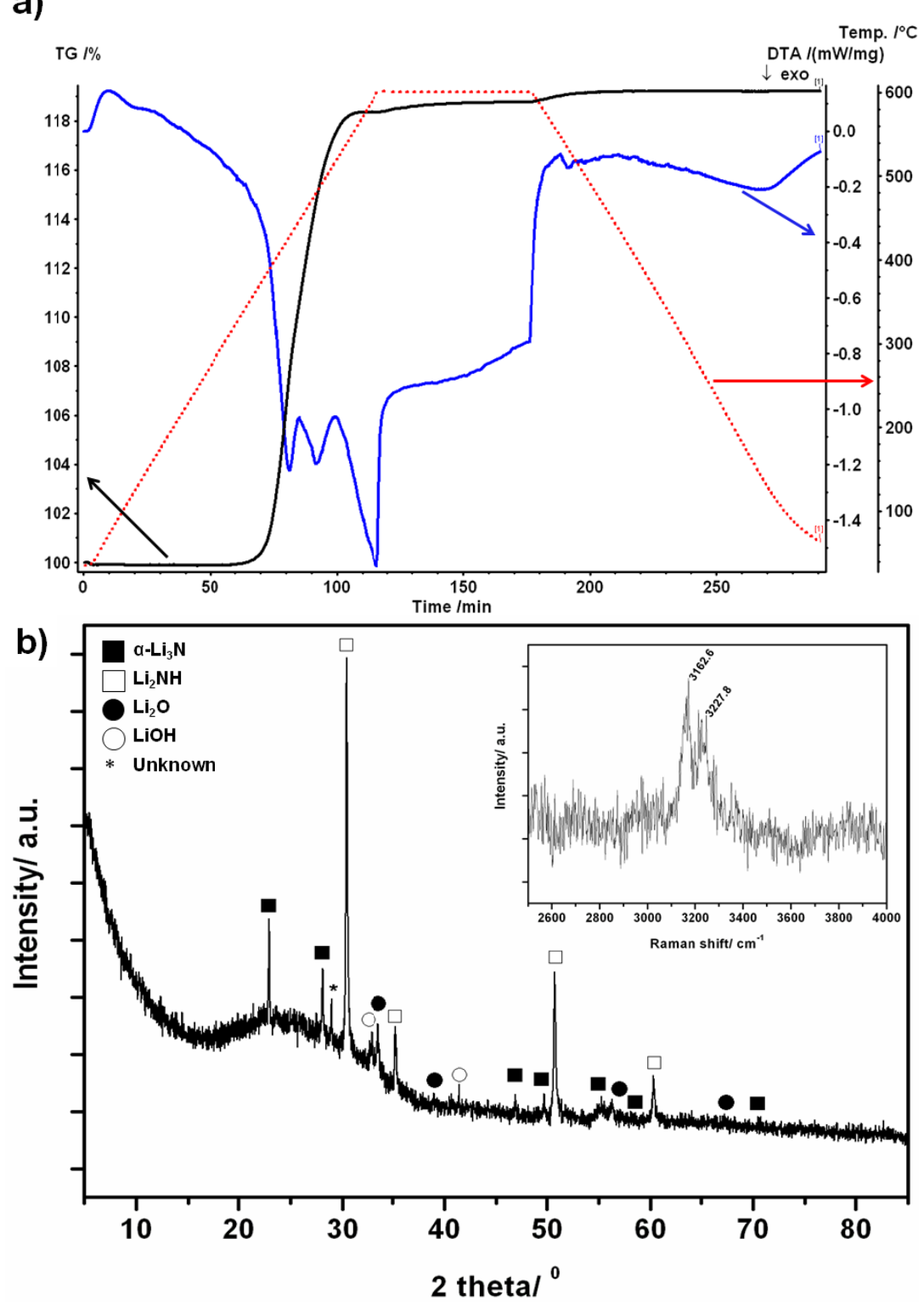


\section{Conclusions}

In summary, $\mathrm{Li}_{4} \mathrm{NH}$ has been synthesized in multi-mode and single-mode cavity microwave reactors over unprecedented timescales. Single-mode microwave reactions demonstrate several advantages over multi-mode approaches, such as increased efficiency and higher reproducibility. This new synthetic approach can reduce reaction times by a factor of 100 compared to conventional synthesis methods. Diffraction data served to confirm the purity of the as-formed product and to provide a structural model for $\mathrm{Li}_{4} \mathrm{NH}$ by means of Rietveld refinement. Thermal treatment under argon showed that a phase transition to a high temperature cubic anti-fluorite phase occurs at $c a .770 \mathrm{~K}$. HT-Li ${ }_{4} \mathrm{NH}$ contains disordered nitride and hydride anions. In addition, results on the reactivity of $\mathrm{Li}_{4} \mathrm{NH}$ under air and $\mathrm{N}_{2}$ were also shown. In the former case, the nitride hydride reacts to form hydroxides (anhydrous and monohydrated) and subsequently lithium carbonate, under ambient conditions. In the latter case, $\mathrm{Li}_{4} \mathrm{NH}$ reacts to produce $\mathrm{Li}_{3} \mathrm{~N}$ and $\mathrm{Li}_{2} \mathrm{NH}$ at high temperature.

\section{Acknowledgments}

Duncan H. Gregory acknowledges the EPSRC (under grant EP/I022570/1) for funding and WestCHEM and ScotCHEM for studentships for Natalie Sorbie and Nuria Tapia-Ruiz respectively.

\section{Conflicts of Interest}

The authors declare no conflict of interest.

\section{References}

1. Chen, P.; Xiong, Z.; Luo, J.; Lin, J.; Tan, L. Interaction of hydrogen with metal nitrides and imides. Nature 2002, 420, 302-304.

2. Weidner, E.; Bull, D.J.; Shabalin, I.L.; Keens, S.G.; Telling, M.T.F.; Ross, D.K. Observation of novel phases during deuteration of lithium nitride from in situ neutron diffraction. Chem. Phys. Lett. 2007, 444, 76-79.

3. Bull, D.J.; Weidner, E.; Shabalin, I.L.; Telling, M.T.F.; Jewell, C.M.; Gregory, D.H.; Ross, D.K. Pressure-dependent deuterium reaction pathways in the Li-N-D system. Phys. Chem. Chem. Phys. 2010, 12, 2089-2097.

4. Marx, R. Reindarstellung und kristallstruktur von lithiumnitridhydrid, $\mathrm{Li}_{4} \mathrm{NH}, \mathrm{Li}_{4} \mathrm{ND}$. Z. Anorg. Allg. Chem. 1997, 623, 1912-1916. (In German).

5. Niewa, R.; Zherebtsov, A.D. Redetermination of the crystal structure of tetralithium mononitride monohydride, $\mathrm{Li}_{4} \mathrm{NH}$. Z. Krist. 2002, 217, 317-318.

6. Laugier, J.; Bochu, B. Laboratoire des Materiaux et du Génie Physique de L' Ecole Supérieure de Physique de Grenoble; Available online: http://www.ccp14.ac.uk/ccp/web-mirrors/lmgp-laugierbochu/ (accessed on 4 November 2013).

7. Larson, A.C.; Von Dreele, R.B. Generalized Structure Analysis System (GSAS); LANSCE, MS-H805; Neutron Scattering Center: Los Alamos, NM, USA, 1990. Available online: https://subversion.xor.aps.anl.gov/trac/EXPGUI (accessed on 14 November 2013).

8. Toby, B.H. EXPGUI, a graphical user interface for GSAS. J. Appl. Crystallogr. 2001, 34, 210-213. 
9. Adam, D. Microwave chemistry: Out of the kitchen. Nature 2003, 421, 571-572.

10. Nakamori, Y.; Orimo S.; Tsutaoka, T. Dehydriding reaction of metal hydrides and alkali borohydrides enhanced by microwave irradiation. Appl. Phys. Lett. 2006, 88, 112104-3.

11. Zhang, H.; Geerlings, H.; Lin, J.; Chin, W.S. Rapid microwave hydrogen release from $\mathrm{MgH}_{2}$ and other hydrides. Int. J. Hydrog. Energy 2011, 36, 7580-7586.

12. Nakamori, Y.; Matsuo, M.; Yamada, K.; Tsutaoka, T.; Orimo, S. Effects of microwave irradiation on metal hydrides and complex hydrides. J. Alloy. Compd. 2007, 446-447, 698-702.

13. Rao, K.J.; Vaidhyanathan, B.; Ganguli, M.; Ramakrishnan, P.A. Synthesis of inorganic solids using microwaves. Chem. Mater. 1999, 11, 882-895.

14. Taylor, M.; Atri, B.S.; Minhas, S.; Bisht, P. Developments in Microwave Chemistry; Evalueserve: Saratoga, CA, USA, 2005. Available online: http://www.rsc.org/images/evaluserve_tcm18-16758.pdf (accessed on 14 November 2013).

15. Boukamp, B.A.; Huggins, R.A. Fast ionic conductivity in lithium nitride. Mater. Res. Bull. 1978, $13,23-32$.

16. Gregory, D.H. Lithium nitrides, imides and amides as lightweight, reversible hydrogen stores. J. Mater. Chem. 2008, 18, 2321-2330.

17. Harrison, A.; Ibberson, R.; Robb, G.; Whittaker, G.; Wilson, C.; Youngson, D. In situ neutron diffraction studies of single crystals and powders during microwave irradiation. Faraday Discuss. 2003, 122, 363-379.

18. CRC Handbook of Chemistry and Physics, 61st ed.; Weast, R.C., Astle, M.J., Eds.; CRC Press, Inc.: Boca Raton, FL, USA, 1980.

19. Balogh, M.P.; Jones, C.Y.; Herbst, J.F.; Hector, L.G. Jr.; Kundrat, M. Crystal structures and phase transformation of deuterated lithium imide, $\mathrm{Li}_{2} \mathrm{ND}$. J. Alloy. Compd. 2006, 420, 326-336.

20. Sichla, T.; Jacobs, H. Synthesis and crystal structure of a calcium nitride deuteride Ca $\mathrm{C}_{2}$ ND. Eur. J. Solid State Inorg. Chem. 1995, 32, 49-56.

21. Brice, J.-F.; Motte, J.-P.; Courtois, A.; Protas, J.; Aubry, J. Etude structurale de $\mathrm{Ca}_{2} \mathrm{NH}$ par diffraction des rayons $\mathrm{X}$, diffraction des neutrons et resonance magnétique nucléaire du proton dans le solide. J. Solid State Chem. 1976, 17, 135-142. (In French).

22. Sichla, Th.; Altorfer, F.; Hohlwein, D.; Reimann, K.; Steube, M.; Wrzesinski, J.; Jacobs, H. Kristallstrukturbestimmung an einer strontium-hydrid-imid-nitrid-phase-Sr $r_{2}(\mathrm{H}) \mathrm{N} / \mathrm{SrNH}$ bzw. $\mathrm{Sr}_{2}$ (D)N/SrND-mit röntgen-, neutronen-und synchrotron-strahlung. Z. Anorg. Allg. Chem. 1997, 623, 414-422. (In German).

23. Altorfer, F.; Bührer, W.; Winkler, B.; Coddens, G.; Essmann, R.; Jacobs, H. $\mathrm{H}^{-}$-jump diffusion in barium-nitride-hydride $\mathrm{Ba}_{2} \mathrm{NH}$. Solid State Ion. 1994, 70-71, 272-277.

24. Bailey, A.S.; Hughes, R.W.; Hubberstey, P.; Ritter, C.; Smith, R.I.; Gregory, D.H. New ternary and quaternary barium nitride halides; synthesis and crystal chemistry. Inorg. Chem. 2011, 50, 9545-9553.

25. Seibel, H.; Wagner, T.R. Preparation and crystal structure of $\mathrm{Ba}_{2} \mathrm{NF}$. J. Solid State Chem. 2004, 177, 2772-2776.

26. Gregory, D.H. Nitride chemistry of the s-block elements. Coord. Chem. Rev. 2001, 215, 301-345. 
27. Crivello, J.-C.; Gupta, M.; Černý, R.; Latroche, M.; Chandra, D. Density functional study of $\mathrm{Li}_{4} \mathrm{NH}$ and $\mathrm{Li}_{1.5} \mathrm{NH}_{1.5}$ as intermediary compounds during hydrogenation of $\mathrm{Li}_{3} \mathrm{~N}$. Phys. Rev. 2010, 81, 104113:1-104113:11.

28. Kojima, Y.; Kawai, Y. IR characterizations of lithium imide and amide. J. Alloy. Compd. 2005, 395, 236-239.

29. Varin, R.A.; Jang, M.; Polanski, M. The effects of ball milling and molar ratio of LiH on the hydrogen storage properties of nanocrystalline lithium amide and lithium hydride $\left(\mathrm{LiNH}_{2}+\mathrm{LiH}\right)$ system. J. Alloy. Compd. 2010, 491, 658-667.

(C) 2013 by the authors; licensee MDPI, Basel, Switzerland. This article is an open access article distributed under the terms and conditions of the Creative Commons Attribution license (http://creativecommons.org/licenses/by/3.0/). 